\title{
Are the recommendations of paediatricians about complementary feeding aligned with current guidelines in Uruguay?
}

\author{
Leticia Vidal ${ }^{1, *}$, Isabel Bove ${ }^{2}$, Gerónimo Brunet ${ }^{3}$, Alejandra Girona ${ }^{4}$, Florencia Alcaire ${ }^{1}$, \\ Lucía Antúnez ${ }^{1}$ and Gastón Ares ${ }^{1}$ \\ 'Sensometrics \& Consumer Science, Instituto Polo Tecnológico de Pando, Facultad de Química, Universidad de la \\ República, By Pass de Rutas 8 y 101 s/n, CP 91000 Pando, Canelones, Uruguay: ${ }^{2}$ UNICEF Uruguay, Montevideo, \\ Uruguay: ${ }^{3}$ Espacio Interdisciplinario, Universidad de la República, Montevideo, Uruguay: ${ }^{4}$ Departamento de \\ Nutrición Básica, Escuela de Nutrición, Universidad de la República, Montevideo, Uruguay
}

Submitted 12 August 2020: Final revision received 21 November 2020: Accepted 23 December 2020: First published online 8 January 2021

\begin{abstract}
Objective: To explore Uruguayan paediatricians' personal recommendations about complementary feeding and to assess if they are aligned with current guidelines and scientific evidence.

Design: A questionnaire composed of open-ended questions was used to explore foods recommended to start complementary feeding, foods regarded as the most important during the first meals, recommendations for delayed introduction of foods and foods that should be avoided. Reasons underlying the recommendations were also explored.

Setting: Montevideo, the capital city of Uruguay (Latin America).

Participants: A total of 212 paediatricians were recruited during a National Pediatrics Conference, organised by the Uruguayan Society of Pediatrics.

Results: The recommendations about complementary feeding provided by paediatricians to parents and caregivers in Uruguay seemed not to be fully aligned with the guidelines provided by the Ministry of Health. Paediatricians recommend a rigid food introduction sequence, characterised by the early introduction of soft pureed vegetables and fruits, followed by meat and the delayed introduction of allergenic foods. Food diversity and the concept of ultra-processed were not frequently identified in the responses.

Conclusions: Results stress the importance of developing educational and communication approaches targeted at paediatricians to contribute to the uptake of updated recommendations regarding complementary feeding.
\end{abstract}

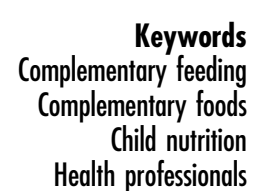

Optimal nutrition during the first 1000 days of life is essential to enable children to achieve their full potential ${ }^{(1)}$. However, childhood malnutrition is still one of the most important public health problems the world faces ${ }^{(2)}$. Globally, the three most visible forms of malnutrition, stunting, wasting and overweight affect at least one in three children under 5 years old ${ }^{(3)}$.

The transition from exclusive breast-feeding or formula feeding to family foods is a particularly vulnerable period in the life of infants ${ }^{(1,4)}$. Complementary feeding can be defined as the introduction of solid and liquid foods other than breast milk or breast-milk substitutes once breast-feeding is no longer sufficient to meet the nutritional requirements of infants ${ }^{(5,6)}$. It should be timely, safe, adequate in terms of amount and variety to provide sufficient nutrients to meet nutritional needs, suitable for the age, and given according to the signals of appetite and satiety $^{(7)}$. The introduction of adequate complementary foods shapes preferences, favours the development of healthy eating habits and can provide protection against obesity and chronic diseases throughout life ${ }^{(8,9)}$.

Inadequate complementary feeding practices such as the early or delayed introduction of solid food, low dietary diversity, insufficient meal frequency and low consumption 
of fruits, vegetables and foods of animal origin (meat, dairy, fish and eggs) have been reported to be highly prevalent worldwide ${ }^{(10)}$. In addition, consumption of ultra-processed products has been recently identified as increasingly prevalent during complementary feeding ${ }^{(3,11)}$. Ultra-processed products are frequently consumed by a large proportion of children from an early age, replacing natural and healthy foods ${ }^{(12,13)}$. Results from a cross-sectional survey conducted in Cambodia, Nepal, Senegal and Tanzania showed that $16-23 \%$ of children 6-23 months had consumed sugar-sweetened beverages the day prior to the interview ${ }^{(14)}$.

The introduction of solid foods has been reported to be a stressful period for parents, who frequently seek for information about complementary feeding to inform their own practices ${ }^{(15,16)}$. Lack of knowledge about complementary feeding has been identified as one of the causes of inadequate feeding practices ${ }^{(11,17)}$. For this reason, advice to caregivers and educational interventions have been recognised as a cornerstone strategy to promote adequate complementary feeding practices ${ }^{(18)}$. Indicators related to access to health and nutrition counselling (e.g. number of antenatal clinic visits and timing of post-natal checkup visits) have been reported to be predictors of adequate complementary feeding practices ${ }^{(19)}$. In addition, research has associated counselling with increased knowledge of caregivers, as well as improved infant feeding practices and growth-related outcomes ${ }^{(17,20-22)}$.

Health professionals have been reported to be the main source of information about complementary feeding for parents and caregivers ${ }^{(15,23)}$. Parents acquire knowledge about feeding practices through the advice provided by health professionals in the context of the health care system $^{(11)}$. Therefore, the knowledge of health professionals, and particularly paediatricians, is crucial for achieving optimal complementary feeding practices. However, the knowledge, beliefs and recommendations of health professionals about complementary feeding have not been explored in-depth yet ${ }^{(24,25)}$.

Previous research has shown that the advice parents receive about feeding practices from health professionals is sometimes incorrect and inconsistent ${ }^{(24-27)}$. According to Alcutt et al. ${ }^{(24)}$, health professionals do not always find it easy to keep up to date with emerging recommendations. Thus, deviations from the recommendations are expected to be more likely for those aspects of complementary feeding for which new scientific evidence has recently emerged. This is the case of recommendations related to the lack of rigid food introduction sequences, introduction of common allergens or gluten for preventing the development of allergic diseases, baby-led weaning and avoidance consumption of ultra-processed foods ${ }^{(27-30)}$. In addition, it should be taken into account that the recommendations provided by paediatricians to caregivers are not only shaped by scientific evidence but also by their professional experiences and beliefs ${ }^{(31)}$.

\section{Aims of the study and context}

In this context, the aims of the present work were to explore Uruguayan paediatricians' personal recommendations about complementary feeding and to assess if they are aligned with current guidelines and scientific evidence.

The study was conducted in Uruguay, a high-income country located in the south-eastern part of South America with a total population of 3.5 million people (93\% living in urban areas). One of the main nutritional challenges in the country is the high prevalence of overweight and obesity in childhood, which coexists with some degree of undernutrition. According to the cohort 2018 of the national survey on infant nutrition, development and health status, $15 \%$ of children between 0 and 4 years old are overweight or obese, while stunting affects $7 \cdot 2 \%{ }^{(32)}$. Fe deficiency in early childhood is also a relevant problem in Uruguay. The last national survey, conducted in 2011, showed that the prevalence of anaemia among children under 24 months old was estimated in $31.5 \%$, while a more recent study reported a prevalence of anaemia of $18.3 \%$ among 8-12 months children ${ }^{33,34)}$. Regarding complementary feeding, the most relevant problems are related to the type of food consumed. In particular, low variety, low consumption of fruits, vegetables and meat, and relatively high consumption of ultra-processed foods rich in sugar, salt and fat ${ }^{(35)}$.

According to the Uruguayan recommendations, newborns receive monthly medical follow-up from paediatricians during the first 6 months. In the 5 th month control, paediatricians are expected to provide guidance on complementary feeding ${ }^{(36)}$. National guidelines on complementary feeding for children between 6 and 24 months old provided by the Ministry of Health were last updated in $2014^{(37)}$. In line with recommendations of the $\mathrm{WHO}^{(5)}$, the guideline stresses the importance of exclusive breastfeeding during the first 6 months of life, establishing 6 months as the appropriate age of introduction of complementary foods. One of the first chapters of the guideline is focused on the opportunity to shape healthy eating habits through an adequate complementary feeding, emphasising consumption of home-made meals based on natural and minimally processed foods, without addition of salt and sugar or honey. Avoiding ultra-processed foods and beverages and other foods rich in sugar, salt, fat and with added sweeteners is also recommended. The guidelines also establish that a variety of natural and minimally processed foods should be offered from the beginning of complementary feeding. No fixed order of first foods is recommended, but special emphasis is made on the inclusion of meat and other Fe-rich foods from the beginning to prevent anaemia. In addition, it is explicitly stated that the introduction of foods regarded as potential allergens should not be delayed beyond the 6 months of age. Additionally, the guideline highlights the importance of responsive feeding, that is being sensitive to the child's cues of hunger and satiety and acting accordingly. 
Regarding the way of introduction of solid foods, Uruguayan national guidelines follow recommendations from the WHO, which state that feeding should start with purees and gradually increase the consistency following the child's development of chewing and swallowing abilities $^{(5,38)}$. An alternative approach to the introduction of solid foods, known as baby-led weaning, was introduced in the UK in the early 2000s and has gained popularity in the last two decades ${ }^{(39)}$. In the baby-led weaning approach, instead of spoon-feeding soft purees, infants are rather encouraged to self-feeding table foods in the form of soft small pieces ${ }^{(39)}$.

\section{Materials and methods}

\section{Participants}

Participants were recruited during a National Pediatrics Conference, organised by the Uruguayan Society of Pediatrics, which was held in Montevideo in October 2019. A stand was placed at the conference lobby, and attendees were invited to complete a short self-administered questionnaire during conference breaks. The questionnaire was completed by 277 people, of which sixty-five were nurses, medicine students or paediatric residents. For this study, only data from the 212 participants who reported to be paediatricians were considered. A summary of the characteristics of the participants is provided in Table 1 . The large proportion of female participants responds to the population paediatricians in Uruguay ( $90 \%$ of graduated paediatricians between 2011 and 2014 were female) $)^{(40)}$. All participants signed an informed consent form before completing the questionnaire and did not receive any compensation.

\section{Procedure}

Considering that the onset of complementary feeding is mostly aligned with the recommendations ${ }^{(32,33)}$, the study

Table 1 Characteristics of the participants of the study $(n 212)$

\begin{tabular}{lcc}
\hline Characteristics & $\begin{array}{c}\text { Number of } \\
\text { participants }\end{array}$ & $\begin{array}{c}\text { Percentage of } \\
\text { participants }\end{array}$ \\
\hline Gender & & \\
Male & 15 & 7 \\
Female & 197 & 93 \\
Age (years) & & \\
26-35 & 59 & 28 \\
36-45 & 76 & 36 \\
46-55 & 47 & 22 \\
$56-67$ & 30 & 14 \\
Years of experience & & \\
$0-5$ & 66 & 31 \\
6-10 & 55 & 26 \\
11-20 & 57 & 27 \\
More than 20 & 34 & 16 \\
Type of health facility & & 8 \\
Public & 17 & 40 \\
Private & 84 & 52 \\
Both & 111 & \\
\hline
\end{tabular}

was focused on the types of foods recommended to introduce, delay and avoid. The questionnaire, presented on paper ballots, comprised five main questions related to complementary feeding. The first question was a word association task about the first foods of a baby, which was not included in the present research. The word association task was followed by four open-ended questions: (i) Which food would you recommend to begin complementary feeding? (In Spanish: ¿Con qué comida recomendaría comenzar la alimentación complementaria?); (ii) Which foods are the most important in the first meals? (In Spanish: ¿Qué alimentos son los más importantes en las primeras comidas?); (iii) Which foods would you recommend for delayed introduction during complementary feeding? (In Spanish: ¿Qué alimentos recomendaria introducir tardiamente durante la alimentación complementaria?); (iv) Which foods and beverages would you recommend to avoid during the first meals? (In Spanish: ¿Qué alimentos y bebidas recomendaria evitar en las primeras comidas?). Questions (ii), (iii) and (iv) were followed by an extra open-ended question asking Why?

The final part of the questionnaire consisted of a series of questions to characterise the sample, including age, gender, profession, years of experience and type of health facility in which they work (public, private or both).

\section{Data analysis}

Participants' responses to each of the open-ended questions were analysed separately using content analysis based on inductive coding ${ }^{(41)}$. Two researchers with previous experience in content analysis coded responses into categories as they emerged from the data, and the final categories were established by consensus. Categories mentioned by at least 2 participants (1\%) were retained for further analysis, and all responses provided by a single participant were coded together in a category named others. Data analysis was performed in Spanish. Category names and examples of each category were translated to English for publication.

The percentage of participants who provided responses coded with each of the identified categories was computed. For each of the questions, the $\chi^{2}$ test was used to explore whether the frequency of mention of responses related to the different categories differed according to paediatricians' years of experience and type of health facility in which they worked. Statistical analysis was performed in $\mathrm{R}$ version $4.0 .0^{(42)}$.

\section{Results}

The frequency of mention of the categories identified in the content analysis for each of the questions is shown in Tables 2-5. Results are presented at the aggregate level 
Table 2 Percentage of participants who provided responses coded in each of the categories identified in the content analysis for the question 'which food would you recommend to begin complementary feeding?'

\begin{tabular}{|c|c|c|c|}
\hline \multirow[b]{2}{*}{ Category } & \multirow[b]{2}{*}{ Examples } & \multicolumn{2}{|c|}{ Frequency of mention* } \\
\hline & & $\begin{array}{l}\text { Number of } \\
\text { participants }\end{array}$ & $\begin{array}{l}\text { Percentage of } \\
\text { participants }\end{array}$ \\
\hline Pureé & Pureé, Pureed vegetables, pureed fruits and vegetables, mashed food & 107 & 51 \\
\hline Vegetables & Vegetables, pumpkin, potato, carrots & 89 & 42 \\
\hline Fruits & Fruits, apple, banana, pear & 82 & 39 \\
\hline Meat & Meat, red meat, white meat, chicken, fish, liver & 57 & 27 \\
\hline Cereals & Cereals, grains, flour & 14 & 7 \\
\hline Gradual & Gradual, progressive, one at a time & 12 & 6 \\
\hline Polenta/Pasta/Rice & Polenta, rice, pasta, corn & 11 & 5 \\
\hline Oil & Oil & 10 & 5 \\
\hline Everything & All, all food groups, complete feeding & 8 & 4 \\
\hline No additions & Without salt, no sugar, & 8 & 4 \\
\hline Dairy & Dairy, yogurt, custards & 6 & 3 \\
\hline Soft/Minced & Minced meat, chopped meat, soft consistency & 5 & 2 \\
\hline Specific nutrients & Carbohydrates, proteins, flourine & 4 & 2 \\
\hline Variety & Varied, different vegetables, diverse meats & 4 & 2 \\
\hline Foods to avoid & No honey, no pulses, without seeds, no gluten & 4 & 2 \\
\hline Water & Water & 3 & 1 \\
\hline Lunch & Lunch & 3 & 1 \\
\hline Home-made & Home-made, foods cooked at home & 3 & 1 \\
\hline Savoury & Start with savoury & 3 & 1 \\
\hline Mixed (sweet/savoury) & Mixed (sweet/savoury), sweet and savoury puree & 3 & 1 \\
\hline Baby-led weaning & BLW, Baby-led weaning & 3 & 1 \\
\hline Allergy caution & No allergens, provided no allergy history & 3 & 1 \\
\hline Otherst & $\begin{array}{l}\text { According to family habits, at } 6 \text { months, cooked, undercooked, } \\
\text { orange juice, four meals, legumes, breast-feeding }\end{array}$ & 12 & 6 \\
\hline
\end{tabular}

*Percentages do not sum up $100 \%$ because some responses were coded with more than one category.

†Includes responses provided by a single participant.

Table 3 Percentage of participants who provided responses coded in each of the categories identified in the content analysis for the question 'which foods are the most important in the first meals?'

\begin{tabular}{|c|c|c|c|}
\hline \multirow[b]{2}{*}{ Category } & \multirow[b]{2}{*}{ Examples } & \multicolumn{2}{|c|}{ Frequency of mention* } \\
\hline & & $\begin{array}{l}\text { Number of } \\
\text { participants }\end{array}$ & $\begin{array}{c}\text { Percentage of } \\
\text { participants }\end{array}$ \\
\hline Vegetables & Vegetables, pumpkin, lettuce & 148 & 70 \\
\hline Meat & Meat, red meat, white meat, chicken, fish, liver & 134 & 63 \\
\hline Fruits & Fruits, banana, orange, citrus & 133 & 63 \\
\hline Cereals/Tubers & Cereals, tubers, potato, grains, flour & 49 & 23 \\
\hline Carbohydrates & Carbohydrates, hydrates of carbon & 26 & 12 \\
\hline Proteins & Proteins & 24 & 11 \\
\hline Everything & All, all food groups, complete feeding & 15 & 7 \\
\hline Variety & Varied, variety of vegetables, variety of textures & 15 & 7 \\
\hline Dairy & Dairy, cheese, milk, cow milk & 13 & 6 \\
\hline Minerals & Minerals, rich in $\mathrm{Fe}$, fluorine, $\mathrm{Ca}$ & 13 & 6 \\
\hline Pureed/Soft/Minced & Puree, minced meat, ground beef, semisolid, not hard & 11 & 5 \\
\hline Water & Water & 10 & 5 \\
\hline Oil & Oil & 9 & 4 \\
\hline Fats & Fats, essential fatty acids, $n-3$ & 7 & 3 \\
\hline Vitamins & Vitamins & 6 & 3 \\
\hline Natural & Natural, no preservatives, no colourings & 5 & 2 \\
\hline No addition of salt and sugar & Without salt, no sugar, & 4 & 2 \\
\hline Legumes & Legumes & 3 & 1 \\
\hline Egg & Egg & 3 & 1 \\
\hline Breast milk & Breast milk & 3 & 1 \\
\hline Energy & Energetic food, calories & 3 & 1 \\
\hline Fibre & Fibre & 3 & 1 \\
\hline Home-made & Home-made, foods cooked at home & 3 & 1 \\
\hline Hedonic & Pleasant flavour, pleasant texture, palatability & 3 & 1 \\
\hline Otherst & Raw, cooked, fresh, in season, easy to manipulate, healthy & 13 & 6 \\
\hline
\end{tabular}

*Percentages do not sum up $100 \%$ because some responses were coded with more than one category.

tIncludes responses provided by a single participant. 
Table 4 Percentage of participants who provided responses coded in each of the categories identified in the content analysis for the question 'which foods would you recommend for delayed introduction during complementary feeding?'

\begin{tabular}{|c|c|c|c|}
\hline \multirow[b]{2}{*}{ Category } & \multirow[b]{2}{*}{ Examples } & \multicolumn{2}{|c|}{ Frequency of mention* } \\
\hline & & $\begin{array}{l}\text { Number of } \\
\text { participants }\end{array}$ & $\begin{array}{l}\text { Percentage of } \\
\text { participants }\end{array}$ \\
\hline Allergens & Allergens, allergenics, those that cause allergy & 58 & 27 \\
\hline Fish and seafood & Fish, seafood & 46 & 22 \\
\hline Red berries & Strawberry, red berries & 40 & 19 \\
\hline Kiwifruit, citrus & Kiwifruit, citrus, orange, fruits rich in vitamin $\mathrm{C}$ & 39 & 18 \\
\hline None & None, everything can be included from the beginning & 37 & 17 \\
\hline Processed/ultra-processed & Processed, ultra-processed, industrialised, manufactured & 28 & 13 \\
\hline Egg & Egg & 22 & 10 \\
\hline Allergy history & Take into account family allergy history, intolerance, allergies & 21 & 10 \\
\hline Leafy greens & Leafy greens, spinach, chard & 17 & 8 \\
\hline Nuts & Nuts, peanuts & 16 & 8 \\
\hline Tomato & Tomato & 14 & 7 \\
\hline Cereals, flour & Cereals, gluten, bread, baked goods, flour & 13 & 6 \\
\hline Sugar, sugary products & Sugar, sugary products, sweet foods & 13 & 6 \\
\hline Dairy & Cow milk, dairy & 8 & 4 \\
\hline Salt, salty products & Salt, salty products & 8 & 4 \\
\hline Legumes & Legumes, lentils & 6 & 3 \\
\hline Honey & Honey & 6 & 3 \\
\hline $\begin{array}{l}\text { None among the } \\
\text { healthy ones }\end{array}$ & $\begin{array}{l}\text { Everything from the beginning provided they are healthy, } \\
\text { among the recommended foods }\end{array}$ & 5 & 2 \\
\hline Beetroot & Beetroot & 5 & 2 \\
\hline Nitrites & Nitrites, foods rich in nitrites & 4 & 2 \\
\hline Meat & Meat & 4 & 2 \\
\hline Processed meat products & Processed meat products & 4 & 2 \\
\hline Fried & Fried foods & 4 & 2 \\
\hline Candies & Candies & 3 & 1 \\
\hline Foods poor in nutrients & Foods poor in nutrients, soups & 2 & 1 \\
\hline Otherst & Juices, textures difficult to process, starchy foods, spicy, fatty foods & 8 & 4 \\
\hline
\end{tabular}

*Percentages do not sum up $100 \%$ because some responses were coded with more than one category.

tIncludes responses provided by a single participant.

Table 5 Percentage of participants who provided responses coded in each of the categories identified in the content analysis for the question 'which foods and beverages would you recommend to avoid during the first meals?' 
as no significant differences were found in the frequency of mention of the categories in any of the questions according to paediatricians' years of experience or type of health facility in which they worked (all $P$-values $\geq 0 \cdot 157$ ). In the following sections, the main results are presented.

\section{Foods recommended to begin complementary feeding}

A total of twenty-three categories were identified in the content analysis of the responses to the first question, related to paediatricians' recommendations to start complementary feeding. As shown in Table 2, the most frequently mentioned categories were pureé (51\%), vegetables ( $42 \%)$, fruits (39\%) and meat (27\%). Other foods were mentioned by a lower percentage of participants including: cereals (7\%), polenta/pasta/rice (5\%), oil (5\%), dairy products (3\%) and water (1\%). A small percentage of paediatricians mentioned in their responses that all food groups are recommended to begin complementary feeding (everything, $4 \%$ ), while some of them mentioned specific nutrients rather than foods (2\%). Also, few participants included references to variety, the preference of homemade food with no additions of salt and sugar, recommendations on starting complementary feeding with savoury or with mixed (sweet/savoury) foods and during lunch (Table 2).

Some of the responses were related to the approach for introducing complementary foods to infants. As previously mentioned, the traditional approach of introducing pureed food was overwhelmingly dominant (pureé, $51 \%$; soft/minced foods, $2 \%$ ). Only $1 \%$ of the paediatricians (3 out of 212) mentioned baby-led weaning. Besides, $6 \%$ of the paediatricians indicated in their responses that they recommended a gradual introduction of complementary foods.

\section{Foods regarded as the most important in the first meals of a baby}

There was high agreement among the paediatricians on the foods which are deemed the most important in the first meals of a baby (Table 3). Vegetables were mentioned by $70 \%$ of the participants, followed by meat (63\%) and fruits (63\%). Cereals and tubers were mentioned in $23 \%$ of the responses, and more that $10 \%$ of paediatricians mentioned carbohydrates and proteins. Other food groups (e.g. dairy, water, oil) as well as other nutrients (e.g. minerals, fats and vitamins) were mentioned by a lower percentage of participants (Table 3). The consideration that all food groups are important in the first meals of a baby was explicitly mentioned by $7 \%$ of the paediatricians, while the same percentage of responses stressed the importance of variety. A small percentage of participants mentioned other characteristics of foods regarded as important, including pureed, soft or minced (5\%), natural (2\%), with no addition of salt or sugar (2\%) and bomemade (1\%).
When asked to explain the reasons underlying their responses, most participants included references to nutritional composition, including nutritional contribution (32\%), vitamins (20\%), iron (20\%), minerals (10\%), protein (10\%), energy (15\%), micronutrients (6\%), macronutrients (2\%), carbobydrates (4\%) and fiber (4\%) content. Concepts such as diet quality (e.g. 'healthy foods', 'adequate' and 'balanced') and variety were mentioned by $9 \%$ and $8 \%$ of paediatricians, respectively. Categories related to physical health were also mentioned in the reasons for considering certain foods as important, such as the relevance of those foods for child growth and development (9\%) and for anaemia prevention (8\%), easy to digest (4\%) and neurological development (2\%).

Moreover, some of the paediatricians indicated in their responses reasons such as providing different textures (9\%) and flavours (8\%), making the meals pleasurable (11\%), and that the foods regarded as important are relevant for learning to eat (11\%).

Some of the reasons for regarding certain foods as important were clearly related to specific foods. In particular, the great majority of responses including as reasons iron content, protein content and anaemia prevention were provided by participants who had considered meat as one of the most important foods (95, 100 and $88 \%$, respectively).

\section{Foods recommended for delayed introduction}

Table 4 presents the twenty-six categories identified in the content analysis of responses to the question: what foods would you recommend for delayed introduction during complementary feeding? Only $17 \%$ of the paediatricians explicitly answered that none of the foods should be introduced with delay, and $2 \%$ stressed the fact that this recommendation was for healthy foods. Examples of such responses are: 'none of the suggested ones (fruits, vegetables, cereals, meat, dairy)' and 'among the healthy ones, none'. The main reason for this recommendation was that children should eat everything.

As shown in Table 4, $27 \%$ of the paediatricians indicated that they would recommend the delayed introduction of allergens, while foods like fish and seafood, red berries and kiwifruit and citrus were mentioned in 18-22\% of responses. Other natural foods, such as egg, nuts, tomato and cereals/flour, were mentioned by $6-10 \%$ of the paediatricians. Allergy prevention was the main reason that paediatricians mentioned to justify the delayed introduction of all these foods and was mentioned by $49 \%$ of paediatricians. Leafy greens were indicated for delayed introduction by $8 \%$ of participants, mainly due to their nitrite content and risk of kidney overload and MetHb syndrome.

Processed and ultra-processed foods were mentioned as foods for delayed introduction by $13 \%$ of paediatricians, whereas sugar or sugary products, and salt or salty products were included in $6 \%$ and $4 \%$ of responses, 
respectively. Various reasons for these recommendations were identified in the content analysis of the $w$ by question, but they were mentioned by a small percentage of participants. Examples are: not healthy/nutritive (5\%), high sugar content (3\%), obesity/overweight prevention (3\%), disease prevention (3\%), high fat content (2\%) and cardiovascular disease prevention (2\%). The rest of the identified categories were mentioned in $<5 \%$ of the responses (Table 4).

\section{Foods and beverages that should be avoided in the first meals of a baby}

The twenty-one categories identified in the content analysis of responses about foods and beverages that should be avoided in the first meals of a baby are shown in Table 5. A large percentage of paediatricians indicated that they recommend to avoid sweetened beverages (62\%), such as 'artificial juices' and 'soft drinks'. Processed and ultra-processed products were mentioned in $41 \%$ of the responses. In fact, $15 \%$ of the paediatricians literally wrote down the term ultra-processed in their answers. Sugar and sugary products (18\%), salt and salty products (16\%) and juices/smoothies (15\%) were also among the foods and beverages that paediatricians recommend to avoid in the first meals of a baby.

The recommendation of avoiding food additives and fried food was mentioned in $8 \%$ of paediatricians' responses. The rest of the identified categories were mentioned by $5 \%$ or less of the participants. Some of these categories included references to specific processed or ultraprocessed foods, such as processed meat products (4\%), snacks (4\%) and candies and alfajores (3\%). Other natural foods (3\%) and natural 'allergenic' foods (foods that had been described as allergenic in the previous responses, $5 \%$ ) were also mentioned by some paediatricians.

When asked to provide the reasons why some foods and beverages should be avoided, many of the responses indicated that these items are harmful (18\%), that they have no nutritional contribution (16\%), are not recommended (8\%) and unnecessary (6\%). Many participants also mentioned the high sugar (18\%), high caloric (16\%), high sodium (9\%) and high fat (8\%) content, as well as the presence of food additives (12\%).

Paediatricians also mentioned as reasons for their recommendations the prevention of overweight and obesity ( $8 \%$ ) and non-communicable diseases (5\%), to encourage good eating habits $(6 \%)$ and to prevent that children get used ( $5 \%$ ) to consuming the foods and beverages that should be avoided. Allergy prevention (8\%) was also mentioned in $8 \%$ of responses.

\section{Discussion}

Paediatricians are a key source of information about complementary feeding for parents and caregivers. The present work explored the recommendations about complementary feeding provided by paediatricians to parents and caregivers in Uruguay. Results showed that although the recommendations were not completely inadequate, they did not fully align with the guidelines provided by the Uruguayan Ministry of Health and by international organisations $^{(5,37,38)}$.

Results from the present study suggest that recommendations tend to be based on a rigid food introduction sequence, despite the fact that national guidelines do not recommend any set order for the first meals ${ }^{(37)}$. Soft pureed vegetables were regarded as the most appropriate foods to start complementary feeding, as well as the most important food during the first meals. Similar results were reported by a recent study conducted in France ${ }^{(43)}$. Interestingly, the variety of vegetables mentioned by the paediatricians was limited and mainly stressed pumpkin, potatoes and carrots. Additionally, specific references to variety were mentioned by a minority of respondents. National guidelines stress the importance of food variety since the beginning of complementary feeding ${ }^{(37)}$. Exposure to variety has been associated with vegetable consumption in the first 3 years of life ${ }^{(44)}$. Considering that vegetable consumption among children remains low in Uruguay ${ }^{(35)}$, further emphasis on variety in the discourse of paediatricians could have a positive impact on the diets of Uruguayan children.

Although meat was regarded as one of the most important foods during the first meals due to its Fe content and its contribution to the prevention of Fe deficiency (anaemia), it was not frequently mentioned as one of the foods recommended at the start of complementary feeding. The relevance of the early introduction of Fe-rich foods, such as meat, has been widely reported in literature ${ }^{(45)}$. In fact, national guidelines include a chapter stressing the importance of including meat from the start of complementary feeding(37). However, paediatricians still seem not to recommend meat as the first food to be introduced during complementary feeding. Instead, they tend to recommend its introduction after children have started to consume vegetable or fruit purees. The lack of emphasis on the early introduction of meat in the recommendations of paediatricians could potentially contribute to its late introduction among Uruguayan children. In this regard, a recent study conducted in Uruguay reported that the prevalence of anaemia among 8-12 months children was $18.3 \%$, whereas late introduction of meat was registered in $66 \%$ of the children ${ }^{(34)}$.

Reasons underlying the recommendation of specific foods were mainly related to the nutritional needs of children and food composition. On the contrary, references to pleasure, the development of oral skills, food preferences and food habits were only mentioned by a minority of the participants. A more frequent inclusion of references to pleasure and food preferences in the discourse of paediatricians could contribute to the promotion of optimal complementary feeding practices, as postulated by Pettigrew for the promotion of healthy eating ${ }^{(46)}$. 
Emphasis on pureed and soft foods was observed, particularly when participants were asked to describe the start of complementary feeding. This suggests that spoonfeeding is the most frequently recommended mode of introduction. On the contrary, baby-led weaning or autoweaning was only mentioned by a small percentage of participants. This points out that traditional approaches to complementary feeding are still predominant in the recommendations of Uruguayan paediatricians, whereas baby-led weaning still has a marginal role. Similar results have been reported in previous studies conducted in different countries ${ }^{(43,47-49)}$. This result is probably related to the fact that baby-led weaning has not been introduced as an alternative recommended practice in the national and international guidelines on complementary feeding ${ }^{(5,37,38)}$. However, considering that the popularity of baby-led weaning is increasing worldwide, paediatricians should be aware of its benefits (e.g. healthier eating patterns) and risks (e.g. low iron intake) to provide appropriate counselling to parents ${ }^{(50-53)}$. In addition, references to the need to expose the child to a variety of textures during complementary feeding were also limited to a small percentage of paediatricians.

Delayed introduction of allergenic food was a highly prevalent recommendation among paediatricians, in line with traditional recommendations ${ }^{(30)}$. Fish, citruses, kiwifruit, strawberry and eggs were frequently mentioned, in agreement with the fact that they have been traditionally maligned foods, although there is no scientific evidence to delay their introduction ${ }^{(28,30,54)}$. In recent years, the recommendation to delay the introduction of common allergens has been modified by early introduction, as new evidence has suggested a potential reduction in the risk of allergic responses ${ }^{(54-58)}$. Although national guidelines recommend the early introduction of potentially allergenic foods, a great proportion of paediatricians seemed to have not incorporated the update in their practice. Lack of familiarisation with this specific recommendation has been reported by other authors ${ }^{(27,43,59)}$.

Sweetened beverages were identified as the main food and beverages to avoid during the first meals, in agreement with current recommendations and their high consumption among Uruguayan children ${ }^{(28,30,35,37)}$. Processed and ultraprocessed foods were the second most frequently mentioned category to avoid. However, only a minority of the participants explicitly referred to ultra-processed products. Most of the specific foods mentioned by participants are clearly associated with ultra-processed products, for example, sweetened beverages, processed meat products and snacks ${ }^{(60)}$. However, other less obvious ultra-processed products frequently consumed by children, such as yogurt, milk desserts, and cookies, were not mentioned. This suggests the need to develop strategies to further familiarise paediatricians with the concept of ultra-processed products in order to facilitate their identification.
Finally, it is important to acknowledge the limitations from the present study. Paediatricians' recommendations on complementary feeding were explored using openended questions, which were mainly focused on foods and beverages recommended to introduce, delay or avoid. Thus, recommendations other than specific foods and beverages, such as variety, approach of introduction of complementary foods, references to pleasure and development of preferences and oral skills are probably underrepresented. Further research is needed to explore more in-depth paediatrician's recommendations on complementary feeding.

\section{Conclusions}

The recommendations about complementary feeding provided by paediatricians to parents and caregivers in Uruguay seemed to be not fully aligned with the guidelines provided by the Ministry of Health. Paediatricians tended to recommend a rigid food introduction sequence, characterised by the early introduction of soft pureed vegetables and fruits, followed by meat and the delayed introduction of allergenic foods. Although specific ultra-processed products were identified as the main category to avoid during the first meals, only a minority of the participants explicitly referred to ultra-processed products.

Results from the present study stress the importance of developing educational and communicational approaches with a strong interdisciplinary emphasis targeted at paediatricians to contribute to the uptake of updated recommendations regarding complementary feeding. Considering that paediatricians have been identified as a key source of information during complementary feeding, the aforementioned approaches could contribute to the promotion of optimal eating habits in early childhood. Further research should be conducted to explore how the recommendations provided by paediatricians influence the complementary feeding practices of parents and caregivers.

\section{Acknowledgements}

Acknowledgements: N/A. Financial support: Funding was obtained from UNICEF Uruguay, Comisión Sectorial de Investigación Científica (Universidad de la República, Uruguay), Instituto Nacional de Alimentación (Ministerio de Desarrollo Social) and Espacio Interdisciplinario (Universidad de la República, Uruguay). UNICEF Uruguay participated in the design/conduct of the study and preparation/review/approval of the manuscript. The rest of the funding institutions had no role in the design, analysis or writing of this article. Conflict of interest: The authors declare no conflict of interest. Authorship: All authors 
contributed to the development of the research. L.V., G.B. and G.A. analysed the data. G.A., L.V., G.B. and A.G. prepared a first version of the paper, to which all other authors then contributed substantially. Ethics of human subject participation: This study was conducted according to the guidelines laid down in the Declaration of Helsinki and all procedures involving human subjects. The experimental protocol was approved by the Ethics Committee of the School of Chemistry of Universidad de la República (Uruguay). Written informed consent was obtained from all participants.

\section{References}

1. Hoffman D, Arts M \& Bégin F (2019) The "First 1,000 Days+" as key contributor to the double burden of malnutrition. Ann Nutri Metabol 75, 99-102.

2. Swinburn BA, Kraak VI, Allender S et al. (2019) The global syndemic of obesity, undernutrition, and climate change: the lancet commission report. Lancet 393, 791-846.

3. UNICEF (2019) The State of the World's Children 2019. Children, Food and Nutrition: Growing Well in a Changing World. New York: UNICEF.

4. World Health Organization (2017) Guidance on Ending the Inappropriate Promotion of Foods for Infants and Young Children: Implementation Manual. Geneva: World Health Organization.

5. Pan American Health Organization (2003) Guiding Principles for Complementary Feeding of the Breastfed Child. Washington: Pan American Health Organization.

6. Agostoni C, Decsi T, Fewtrell M et al. (2008) Complementary feeding: a commentary by the ESPGHAN committee on nutrition. J Pediatr Gastr Nutr 46, 99-110.

7. World Health Organization (2002) Complementary Feeding: Report of the Global Consultation, and Summary of Guiding Principles for Complementary Feeding of the Breastfed Child. Geneva: World Health Organization.

8. Cowbrough K (2010) Infant feeding practices in the UK. Complementary feeding for infants 6 to 12 months. J Family Health Care 20, 20-23.

9. Pearce J, Taylor M \& Langley-Evans S (2013) Timing of the introduction of complementary feeding and risk of childhood obesity: a systematic review. Int J Obes 37, 1295-1306.

10. White JM, Bégin F, Kumapley R et al. (2017) Complementary feeding practices: current global and regional estimates. Matern Child Nutr 13, e12505.

11. Bégin F \& Aguayo VM (2017) First foods: why improving young children's diet matter. Matern Child Nutr 13, e12528.

12. Giesta JM, Zoche E, Corrêa RS et al. (2019) Associated factors with early introduction of ultra-processed foods in feeding of children under two years old. Cien Saude Colet $\mathbf{2 4}$, 2387-2397.

13. Lopes WC, de Pinho L, Caldeira AP et al. (2020) Consumption of ultra-processed foods by children under 24 months of age and associated factors. Rev Paul Pediatr 38, e2018277.

14. Pries AM, Huffman SL, Champeny M et al. (2017) Consumption of commercially produced snack foods and sugar-sweetened beverages during the complementary feeding period in four African and Asian urban contexts. Matern Child Nutr 13, e12412.

15. Loudon K, Buchanan S \& Ruthven I (2016) The everyday life information seeking behaviours of first-time mothers. $J$ DOC 72, 24-46.

16. Harrison M, Brodribb W \& Hepworth J (2017) A qualitative systematic review of maternal infant feeding practices in transitioning from milk feeds to family foods. Matern Child Nutr 13, e12360

17. Arikpo D, Edet ES, Chibuzor MT et al. (2018) Educational interventions for improving primary caregiver complementary feeding practices for children aged 24 months and under. Cochrane Database Syst Rev 5, CD011768.

18. World Health Organization (2020) Complementary feeding. https://www.who.int/health-topics/complementary-feeding\# tab=tab_3 (accessed April 2020).

19. Na M, Aguayo VM, Arimond M et al. (2017) Risk factors of poor complementary feeding practices in Pakistani children aged 6-23 months: a multilevel analysis of the Demographic and Health Survey 2012-2013. Matern Child Nutr 13, e12463.

20. Hotz C \& Gibson RS (2005) Participatory nutrition education and adoption of new feeding practices are associated with improved adequacy of complementary diets among rural Malawian children: a pilot study. Eur J Clin Nutr 59, 226-237.

21. Guldan GS, Fan HC, Ma X et al. (2000) Culturally appropriate nutrition education improves infant feeding and growth in rural Sichuan, China. J Nutr 130, 1204-1211.

22. Aguayo VM (2017) Complementary feeding practices for infants and young children in South Asia. A review of evidence for action post-2015. Matern Child Nutr 13, e12439.

23. Garcia AL, Looby S, McLean-Guthrie K et al. (2019) An exploration of complementary feeding practices, information needs and sources. Int J Environ Res Public Health 16, 4311.

24. Alcutt C \& Sweeney MR (2010) An exploration of knowledge, attitudes and advice given by health professionals to parents in Ireland about the introduction of solid foods. A pilot study. BMC Public Health 10, 201.

25. Rubio AM, Cantarero Vallejo MD \& Espín Jaime B (2018) ¿Cómo orientan los pediatras de Atención Primaria la alimentación complementaria? (How do primary care paediatricians guide complementary feeding in Spain?) Rev Pediatr Aten Primaria 20, 35-44.

26. Smale M, Renfrew MJ, Marshall JL et al. (2006) Turning policy into practice: more difficult than it seems. The case of breastfeeding education. Matern Child Nutr 2, 103-113.

27. Leo S, Dean J \& Chan ES (2012) What are the beliefs of pediatricians and dietitians regarding complementary food introduction to prevent allergy? Allergy Asthma Clin Immunol 8, 3.

28. Alvisi P, Brusa S, Alboresi S et al. (2015) Recommendations on complementary feeding for healthy, full-term infants. Ital J Pediatr 41, 36.

29. Monteiro CA, Cannon G, Moubarac J-C et al. (2018) The UN Decade of Nutrition, the NOVA food classification and the trouble with ultra-processing. Public Health Nutr 21, 5-17.

30. Romero-Velarde E, Villalpando-Carrión S, Pérez-Lizaur AB et al. (2016) Guidelines for complementary feeding in healthy infants. Bol Med Hosp Infant Mex 73, 338-356.

31. Calamaro CJ (2000) Infant nutrition in the first year of life: tradition or science? Pediatr Nurs 26, 211-215.

32. Secretaría Técnica de la ENDIS (2019). Primeros resultados de la Encuesta de Nutrición, Desarrollo Infantil y Salud cohorte 2018 (First results of the Survey on Infant Nutrition, Development and Health status cohort 2018). https://www.gub.uy/ministerio-desarrollo-social/sites/ministeriodesarrollo-social/files/documentos/publicaciones/Primeros $\% 20$ resultados\%20de $\% 201 \mathrm{la} \% 20$ Encuesta\%20de\%20Nutrici\%C3\%B 3n\%2C\%20Desarrollo\%20Infantil\%20y\%20Salud_\%20cohorte\% 202018.pdf (accessed November 2020).

33. Bove I \& Cerruti F (2011) Encuesta nacional sobre estado nutricional, prácticas de alimentación y anemia (National Survey on Nutrition Status, Feeding Practices and Anemia). Montevideo: MSP-MIDES-RUANDI-UNICEF.

34. Machado K, Alcarraz G, Morinico E et al. (2017) Anemia ferropénica en niños menores de un año usuarios de CASMU-IAMPP: prevalencia y factores asociados (Iron deficiency anemia in children younger than 1 year old users of 
CASMU-IAMPP: prevalence and associated factors). Arch Pediatr Urug 88, 254-260.

35. Ares G, Vidal L \& Girona A (2018) Patrones de alimentación y asociación con estado nutricional en la población infantil (Eating Patterns and Associations with Nutrition Status in Infant Population). Montevideo: Universidad de la República.

36. Consejo Coordinador de la Educación en la Primera Infancia (2020) Salud y Educación en la Primera Infancia (Health and Education in Early Childhood). https://www.gub.uy/ ministerio-educacion-cultura/sites/ministerio-educacioncultura/files/documentos/publicaciones/librillo-salud-en-primerainfancia-digital.pdf (accessed November 2020).

37. Ministerio de Salud Pública (2017) Guía de alimentación complementaria para niños entre 6 y 24 meses (Guidelines on Complementary Feeding for Children Between 6 and 24 Months Old). Montevideo: Ministeiro de Salud Pública.

38. World Health Organization (2005) Guiding Principles for Feeding Non-Breastfed Children 6-24 Months of Age. Geneva: World Health Organization.

39. Brown A, Jones SW \& Rowan H (2017) Baby-Led weaning: the evidence to date. Curr Nutr Rep 6, 148-156.

40. Troche ME (2019). La feminización de la especialidad de pediatría en la ciudad de Montevideo, Uruguay (The Feminization of Pediatrics Specialty in the City Montevideo, Uruguay). Montevideo: Facultad de Ciencias Sociales, Universidad de la República.

41. Krippendorff K (2004) Content Analysis: An Introduction to Its Methodology. Thousand Oaks, CA: Sage Publications.

42. R Core Team (2020) R: A Language and Environment for Statistical Computing. Vienna: R Foundation for Statistical Computing.

43. Chouraqui JP, Delmas B, Le Bris M et al. (2019) Physicians advice, parental practice and adherence to doctor's advice: an original survey on infant feeding. BMC Pediatr 19, 313 .

44. Barends C, Weenen H, Warren J et al. (2019) A systematic review of practices to promote vegetable acceptance in the first three years of life. Appetite 137, 174-197.

45. Obbagy JE, English LK, Psota TL et al. (2019) Complementary feeding and micronutrient status: a systematic review. Am J Clin Nutr 109, 852S-871S.

46. Pettigrew S (2016) Pleasure: an under-utilised ' $\mathrm{P}$ ' in social marketing for healthy eating. Appetite 104, 60-69.

47. Cameron SL, Heath A-LM \& Taylor RW (2012) Healthcare professionals', and mothers', knowledge of, attitudes to and experiences with, baby-led weaning: a content analysis study. BMJ Open 2, e001542.

48. Lacorte D, Lionetti P, Retetangos C et al. (2018) Complementary feeding during the first year of life in Italy. Medico e Bambino 37, 172-177.

49. Leonelli G, Cavieres P \& Munizaga R (2019) Relationship between knowledge and recommendations of baby-led weaning in primary care settings in the cities of Coquimbo and La Serena, Chile. Rev Chil Nutr 46, 761-767.

50. Moreno Villares JM, Galiano Segovia MJ \& Dalmau Serra J (2013) Baby-Led weaning, a valid approach to complementary feeding? Acta Pediatr Esp 71, 99-103.

51. Brown A \& Lee M (2011) A descriptive study investigating the use and nature of baby-led weaning in a UK sample of mothers. Matern Child Nutr 7, 34-47.

52. Cameron SL, Taylor RW \& Heath ALM (2013) Parent-Led or baby-led? Associations between complementary feeding practices and health-related behaviours in a survey of New Zealand families. BMJ Open 3, 1-9.

53. Morison BJ, Taylor RW, Haszard JJ et al. (2016) How different are baby-led weaning and conventional complementary feeding? a cross-sectional study of infants aged 6-8 months. BMJ Open 6, e010665.

54. EFSA Panel on Nutrition, Novel Foods and Food Allergens (NDA), Castenmiller J et al. (2019) Appropriate age range for introduction of complementary feeding into an infant's diet. EFSA J 17, e05780.

55. De Silva D, Geromi M, Halken S et al. (2014) Primary prevention of food allergy in children and adults: systematic review. Allergy 69, 581-589.

56. Muraro A, Halken S, Arshad SH et al. (2014) EAACI Food allergy and anaphylaxis guidelines. Primary prevention of food allergy. Allergy 69, 590-601.

57. Fleischer DM, Sicherer S, Greenhawt M et al. (2015) Consensus communication on early peanut introduction and the prevention of peanut allergy in high-risk infants. Ann Allergy Asthma Immunol 115, 87-90.

58. Togias A, Cooper SF, Acebal ML et al. (2017) Addendum guidelines for the prevention of peanut allergy in the United States: report of the National Institute of Allergy and Infectious Diseases-sponsored expert panel. Allergy Asthma Clin Immunol 13, 1.

59. Vieira SCF, Santos VS, Franco JM et al. (2020) Brazilian pediatricians' adherence to food allergy guidelines - a cross-sectional study. PLoS One 15, e0229356.

60. Ares G, Vidal L, Allegue G et al. (2016) Consumers' conceptualization of ultra-processed foods. Appetite 105, 611-617. 